\title{
Los caminos del desarrollo del tercer mundo al mundo emergente, de Héctor Guillén Romo
}

\section{Carlos Mallorquín*}

La mirada que priva en el libro de Héctor Guillén Romo se declara bajo el influjo de una perspectiva mucho más «fructífera» que la «metodología neoclásica basada en métodos abstractos y deductivos» (2018:24-25):! un «enfoque más concreto, inductivo e interdisciplinario basado en la experiencia histórica» (p. 25). ${ }^{2}$ Apoyándose en Ha-Joon Chang, Guillén propone presentar una visión «heterodoxa» de la «economía del desarrollo», la cual va más allá de catalogar y recolectar «hechos históricos» (p. 25), destacando aquellos aspectos teóricos «pluridisciplinarios» (p. 26) observados en los «pioneros de la década de 1950»: «Pautas históricas permanentes, construir teorías para explicarlas y aplicar estas teorías a problemas contemporáneos, teniendo en cuenta al mismo tiempo los cambios en las circunstancias tecnológicas, institucionales y políticas» (Chang, 2004, en Guillén, 2018:25-26).

Se trata de un texto en torno al pensamiento económico (558 páginas, incluyendo bibliografía e índice de materias), cuya primera parte, casi 50 por ciento, corresponde a los tres primeros capítulos. El lector interesado

\footnotetext{
${ }^{1}$ Véase la explicación en las notas a pie de página 35 y 36; las notas a pie siguen un orden cronológico desde el comienzo hasta el final del texto.

${ }^{2}$ Para una mayor explicación, véase la nota al pie 37.

* Doctorado en Estudios del Desarrollo, Universidad Autónoma de Zacatecas, México.
} 


\section{CARLOS MALLORQUÍN}

exclusivamente en las ideas económicas de los últimos 70 años bien podría cerrar el libro habiendo concluido con la primera parte.

El primer capítulo (pp. 33-143) ${ }^{3}$ corresponde a una revisión, presentación, difusión, de las «Anglo-Saxon economic theories» (Seers, 1979:710) o discursos surgidos en Europa; para mi gusto, fue agradable su lectura porque el autor se remite sistemáticamente a los textos en «francés», cuyo idioma no leo. Le sigue un capítulo donde se ofrece una visión sintética de Perroux y Sen (pp. 144-187) y culmina con el tercer capítulo dedicado a la discusión teórica del pensamiento latinoamericano (pp. 187-244). ${ }^{5}$

La segunda parte del libro se concentra en describir las vicisitudes o «éxitos» de la evolución histórica del «desarrollo»o «crecimiento» especialmente a partir del periodo de posguerra o cuando ha sido necesario iniciando históricamente en épocas previas. El cuarto capítulo (pp. 245$310)^{6}$ realiza el diagnóstico de la evolución económica de ciertas economías del Asia del Este (China, India y los «tigres asiáticos»: Taiwán, Corea del Sur, Hong Kong, Singapur), ${ }^{7}$ en el siguiente capítulo (el quinto, pp. 310-441), ${ }^{8}$ examina de manera similar las consecuencias y estrategias del proceso económico en la región latinoamericana por medio de una exposición histórica de los casos de Argentina, Chile, Brasil, Venezuela, para culminar en el sexto capítulo (pp. 441-502), ${ }^{9}$ con el caso mexicano, cuya

\footnotetext{
${ }^{3}$ «La mirada del pensamiento económico dominante en materia de desarrollo: de los pioneros a las experiencias aleatorias de terreno».

${ }^{4}$ «De Francois Perroux a Amartya Sen: la economía al servicio del hombre».

${ }^{5}$ «El pensamiento económico latinoamericano: el estructuralismo, la nueva Cepal y el nuevo rumbo».

${ }^{6}$ «Estrategias del desarrollo en Asia: los países exitosos».

${ }^{7}$ Sin olvidar «los tigritos» Indonesia y Malasia.

8 «Estrategias de desarrollo en América Latina».

${ }^{9}$ «México: de la industrialización dirigida por el Estado al modelo económico liberal».
} 
amplitud historiográfica y discusión contrasta respecto al espacio dedicado al examen y exposición evolutivo de las formaciones económicas del capítulo anterior. Las pormenorizadas descripciones productivas sectoriales y geográficas facilitan observar aquellos fenómenos históricos y las asimetrías de poder de las categorías de centro-periferia generadas por el pensamiento estructuralista latinoamericano. ${ }^{10}$ Por otro lado, por la fecha de la publicación del libro, en varios ámbitos y políticas críticas discutidas y observadas en México del pasado, no pudieron recibir atención las actuales medidas que el nuevo gobierno recientemente electo ha propuesto, como sería la organización fiscal de Pemex en el ámbito energético, e igualmente con la política de dar por concluidas futuras concesiones territoriales.

$\mathrm{El}$ «Epílogo» ${ }^{11}$ incorpora a las recurrentes comparaciones, para bien o mal, entre las estrategias y políticas económicas impulsadas en América Latina y el Asia del Este, con el fin de resaltar la «exitosa» o «superioridad» de la política económica de los asiáticos (aparentemente su apertura al comercio exterior, exportación de productos manufacturados y menor

${ }^{10}$ Por ejemplo, igualmente, incluso para los EUA: «Las firmas exportadoras representan una pequeña minoría de empresas de un país, el grueso de empresas se vuelcan hacia el mercado doméstico. El sector manufacturero de Estados Unidos representa 20 por ciento de la producción y 8 por ciento del empleo. Las evaluaciones del efecto sobre el empleo americano del TLCAN o de la competencia china muestran que los resultados son extremadamente heterogéneos en el espacio local. Son muy negativos para una minoría: el empleo ha disminuido y el salario ha aumentado menos en las regiones de empleo más afectadas por la competencia, para el caso de los trabajadores no calificados. Por el contrario, los trabajadores calificados no son afectados y a escala del país en su totalidad el efecto de la competencia internacional sobre los empleos y los salarios es muy débil, menor que el de los cambios estructurales como el aumento de la demanda por los servicios y la automatización de la producción. (...) el comercio crea perdedores, pero no todos los perdedores resultan del comercio» (p. 499). Véase la transferencia de tecnología y empresas entre los «tigres» y tigritos (pp. 302-304).

${ }^{11}$ «¿Por qué los países de América Latina tuvieron un comportamiento diferente a los países asiáticos?» 


\section{CARLos Mallorquín}

participación estatal, todo lo cual es problemático) y los «déficits» al respecto en la región latinoamericana. Mucho lugar por lo tanto ocupa primero la interpretación de las políticas económicas regionales y en segundo lugar las respuestas y rumbo que toman las distintas regiones ante los «mandamientos» del Consenso de Washington durante la década de 1990, sustrato de las políticas neoliberales.

La unidad discursiva del libro, especialmente en la primera parte, se debe a una problemática cuya naturaleza, y por lo tanto la visión de la lectura, encuentra sus orígenes en Europa o el mundo académico anglosajón con aquello que se llamó «la economía del desarrollo». Aunque el autor «coquetea» con el estructuralismo latinoamericano, dicho vocabulario no domina la narrativa. No obstante, el autor no deja de señalar el etnocentrismo e insuficiencias conceptuales de las teorías eurocéntricas, como lo hizo en su tiempo el discurso latinoamericano de las décadas de 1940 y 1950.

Con otras palabras, durante las décadas de 1940 y 1950, los supuestos pioneros de la «economía del desarrollo» parten de la idea de que el vocabulario teórico de la «economía» presenta una serie de limitaciones para pensar a la periferia, o países en desarrollo, y por lo tanto proponen discutir la transformación social y sectorial del trabajo de las formaciones económicas a partir de ciertos mecanismos institucionales apoyándose en las políticas estatales para organizar o impulsar la evolución del «mercado» o el crecimiento/desarrollo de la economía. Sin embargo, a mediados de la década de 1970, la evolución del pensamiento económico en los países del centro, Europa y EUA, así como las políticas y estrategias económicas, desplazan la división disciplinaria dual de la «economía», perspectiva que por entonces va siendo hegemonizada por el vocabulario neoliberal, a partir del cual todas 
las formaciones económicas debían diagnosticarse con los mismos instrumentos teóricos, tanto en el centro como en la periferia. Del periodo es importante recordar que es a partir de la corriente neoliberal que en América Latina se genera la leyenda negra sobre las consecuencias de las políticas económicas impulsadas al amparo de un Estado «protector» cuya supuesta ineficiencia puede fácilmente cuestionarse, en términos globales y particulares, al examinar la velocidad con que los capitales extranjeros compraron las empresas públicas durante el proceso de su privatización.

Guillén también describe otras corrientes teóricas como el institucionalismo norteamericano y otras perspectivas que aparentemente redujeron sus «ambiciones» teóricas y prácticas, concentrándose no tanto en promover las transformaciones de la división social-sectorial y territorial del trabajo en el nivel nacional, sino en aquellos aspectos de las políticas que suponen reducir la pobreza. Incorpora exposiciones que parten de visiones teóricas que reivindican la microeconomía, como el caso de la propuesta de Banerjee y Duflo. No está demás subrayar que estas ideas en torno a la economía provenientes de Europa reciben por parte del autor una descripción pormenorizada, mostrando un meticuloso y desesperante estoicismo, no obstante que la mayoría de las teorías presentan un ofensivo etnocentrismo o presupuestos banales sobre la «racionalidad» de los agentes económicos en la periferia.

Quien redacta estas páginas, a partir de un visión latinoamericana de la economía construida en la región por autores llamados «estructuralistas», se regocija con lo que encuentra en el capítulo segundo, el cual examina la obra de Perroux en tándem con la de A. Sen, debido a su parecido familiar con el pensamiento económico latinoamericano, especialmente con Perroux, el cual centra su reflexión al examinar las condiciones de 


\section{CARLOS MALLORQUÍN}

existencia que hacen posible las asimetrías de poder y las estrategias para superarlas o, lo que en términos de Perroux se teoriza a partir de la noción de «la dominación».

Esto nos lleva al capítulo que describe el pensamiento latinoamericano y respecto del cual no tengo «empacho» en decir que el espacio dedicado al mismo no posibilita al autor destacar la pluralidad y diversidad teórica conceptual entre varios de sus impulsores (Prebisch, Furtado, Pinto, Urquidi, Sunkel, Di Filippo, por mencionar algunos, o aquellos que se distinguen como dependentistas, marxistas o no, Marini, Dos Santos, Quijano, Cardoso, etcétera). Sin duda, no puede negarse el esfuerzo titánico de síntesis para reducir su extensión. Antes de proseguir con otros aspectos a destacar en el libro no quiero dejar de señalar que tal vez un elemento teórico con el cual no se tuvo el debido cuidado de presentación fueron las nociones de «centro» $\mathrm{y}$ «periferia», las cuales no suponen necesariamente formaciones económicas distintas, en otras palabras, la propia "periferia», presenta los antagonismos centro-periferia, que pueden observarse entre distintas formaciones económicas: las asimetrías de poder generan los centros y las periferias intra o extra regionales; en otras palabras, la heterogeneidad es consecuencia de las asimetrías de poder, no se trata del grado «tecnológico», de los agentes o zonas en cuestión. La heterogeneidad se da y se encuentra en todas las formaciones económicas, surge como consecuencia de las asimetrías de poder, dichas asimetrías deben examinarse tomando en cuenta las condiciones de existencia de los agentes y las formas en que poseen en separación algunas de dichas condiciones. Es dicha posesión en separación la que hace posible hablar de «mercados», el mecanismo institucional mediante el cual se obtienen (compra-venta o equivalencias de intercambio de todo tipo) los elementos respectivos para gene- 
rar o producir ciertos bienes-productos por un lado, así como establecer los «precios» y niveles de remuneración, proceso inherentemente antagónico. La heterogeneidad de los agentes obedece precisamente a la asimetría de poder para establecer «precios» o equivalencias en los niveles micro o macroeconómico. Los antagonismos surgen a raíz de aquellos aspectos existenciales cuyas condiciones de existencia no están bajo el dominio de los agentes en cuestión (Cfr. Mallorquín, 2017). Aspectos puntuales, que el libro de Guillén demuestra, pero con otro vocabulario, y por tanto sin hacer una referencia explícita, en varias de sus descripciones históricas a lo largo de los procesos económicos en las distintas latitudes geográficas, de la región latinoamericana y del Asia del Este.

El supuesto «milagro» económico asiático, entre diversas formaciones económicas, se expone a partir de contrastar las políticas selectivas de apoyo a diversos sectores e industrias y la apertura comercial, las cuales facilitan su integración a ciertos de sectores productivos de las cadenas globales valor o con la transferencia de ciertos sectores productivos hacia otros ámbitos geográficos del Asia del Este, donde se observan niveles salariales menores, sin excluir un proceso de especialización y ampliación de inversiones en tecnologías en ciertos sectores productivos de «punta» o cercanos a ellas.

En otras palabras, se visualizan dichas políticas, en el sudeste de Asia y se subrayan las diferencias de implementación del catálogo de mandamientos impulsado por el Consenso de Washington, los cuales a su vez también son bien discutidos (pp. 328-331). Si bien en la exposición de la historia económica de esas zonas el autor en ocasiones hace uso del término «éxito», éste debe tomarse con precaución, dadas la desigualdades y ausencia inicial de procesos democráticos para lograrlo. El contexto, de una mayor igual- 


\section{CARLOS MALLORQUÍN}

dad, o si se gusta menor desigualdad, en las décadas de 1990-2010, con una población con un mayor grado de alfabetismo que América Latina, ciertamente hace más factible realizar e implementar políticas económicas más acordes a ciertas tendencias de apertura económica al exterior y una participación selectiva estatal, la cual tampoco se presenta factible en la región latinoamericana, que desmantela casi todo el aparato de apoyo estatal a la industria de origen nacional, sin ninguna previsión de tiempo para su reestructuración, consecuencia a su vez de la crisis de la deuda externa, lo cual explica la «década pérdida» de 1980 sin crecimiento.

Por otra parte, dichas políticas y estrategias en el Este de Asia se logran con un alto grado de autoritarismo, como bien se dice en el libro, pero queda sin subrayar suficientemente el contexto global de las políticas de los EUA, las cuales son mucho más «permisivas» y favorables en dicha zona geográfica, en contraste con las que se observaron hacia América Latina (Fernández, 2017). Igualmente, el «éxito» económico de China en gran parte es una grave calamidad, producto de una inconmensurable pobreza bajo la cual viven dos tercios de su población (800 millones de seres humanos).

La imagen presentada de la evolución económica de la región se sustenta en lo que aparentemente sería una perspectiva elaborada por Prebisch o de la Cepal, con la distinción de un periodo de políticas económicas dirigidas a favorecer el mercado internacional de mercancías como su propulsión central — hacia afuera - al que se le contrapone otro que insistiría en poner mayor énfasis en aspectos socioeconómicos internos — hacia adentro-, entre cuyos objetivos estaría transformar a las sociedades por medio de una serie de políticas que estaban limitadas por la ausencia de las «reformas» fiscal, agraria, educativa e industrial. En otras palabras, hoy se habla 
de una «política industrial» selectivamente calculada; mientras que en la década de 1950 el proceso de «industrialización» formaba parte de una reforma política-social, la cual implícitamente suponía la transferencia del centro de poder y decisiones, entonces en los terratenientes o «coroneles» (Brasil), hacia las ciudades.

De hecho, la industrialización por sustitución de importaciones en los bienes de consumo se logra casi sin impedimentos, en otros casos, en aquellos sectores de mayor envergadura tecnológica o de requerimientos de capital, lo cual supone elevar el grado de inversiones y de recursos importados, impide su plena sustentación en las épocas en que la balanza de pagos sufre un declive de ingresos ante la reducción de los precios por exportaciones. Dicho proceso está tipificado por la asimetría de poder entre los precios de los bienes manufacturados y aquellos correspondientes de los bienes primarios, que por lo general son los que ceden ante una reducción de su demanda para intentar proteger cierto nivel de ingresos por sus exportaciones: el famoso deterioro de los términos de intercambio. Vale la pena insistir en que Prebisch jamás dijo que el deterioro sea o se manifestara cual «ley natural» («no conocemos el futuro» decía), e igualmente de que únicamente se manifestara entre distintas formaciones económicas. Con anterioridad se advirtió que las asimetrías de poder entre los agentes productivos reflejan los antagonismos entre dichos agentes así como sus diversas condiciones de existencia, las cuales limitan o hacen posible defender ciertos niveles de ingresos o precios. La heterogeneidad de los agentes, dadas sus asimétricas y dispares condiciones de existencia y sus respectivos mecanismos antagónicos para su «defensa», es el modelo que guiaba la visión en Prebisch, Furtado, entre otros. Ello explica su rechazo de la noción de los agentes como entidades «representativas» racionales 


\section{CARLOS MALLORQUÍN}

de la economía convencional o neoclásica, así como la noción de equilibrio general.

Es cierto que existe una interpretación de las propuestas de la Cepal y de Prebisch, y del neoestructuralismo, entre otros, la cual podríamos denominar como una suerte de «fetichismo de la industrialización»; sin embargo, fue precisamente la ausencia de reformas sociales ya mencionadas en otros ámbitos sectoriales lo que explica las dificultades de la transformación de la división social-tecnológica y territorial de las formaciones económicas de la periferia, aspectos, cabe de paso destacar, se suceden por la buena o la mala, en el sud este de Asia. En la región latinoamericana, la incontestable presencia de la lucha social, por la instauración de gobiernos más democráticos posterior a la segunda guerra mundial, así como en ocasiones el dominio de los regímenes militares, sin olvidar los gobiernos que se dicen socialistas y revoluciones que adoptan dicha designación, formaron parte del horizonte antagónico económico-social del «malogrado» desarrollo económico regional.

El retorno de un liberalismo «autoritario» un oximoron, y en muchos países, bajo la mano militar en la región, opacó, por no decir extinguió, tanto las ideas renovadoras de posguerra elaboradas en América Latina, así como las prácticas, y políticas promovidas para pensar y evaluar las transformaciones sociales, y no exclusivamente, o necesariamente en torno a la «industrialización».

Por ello en parte, el «Epílogo» del libro, donde se comparan las vicisitudes de América Latina con los países del Sudeste de Asia respecto a sus inserciones al proceso de la «globalización», así como su adopción o no de los mandamientos instaurados por el Consenso de Washington, puede no ser la mejor manera de postular una evaluación o diagnóstico para explicar la evolución de las formaciones económicas en cuestión. 
Antes de terminar, quisiera decir que vale la pena subrayar que si bien el libro presenta un universo muy amplio del vocabulario de la actual economía, una mayor profundización del examen del lenguaje y vocabularios teóricos a partir de los cuales dichos diagnósticos se realizaron, requiere a su vez una mayor intromisión de las ideas cepalinas o de Prebisch, las cuales harían posible una estrategia discursiva hegemónica y alternativa que problematice el uso actual de ciertas categorías económicas. Ello supone, subsecuentemente, reconfigurar, desplazar, superar (en términos hegelianos) para proponer políticas alternativas. Igualmente problematizar la existencia de nociones generales sobre el supuesto reino del «capitalismo», como totalidad o entidad autosustentada, y rescatar la heterogeneidad y el antagonismo consustancial entre los agentes (formaciones económicas, regiones, empresas, individuos, o sea, los agentes quienes a su vez no todos son «humanos») para repensar reformas y políticas específicas para cada caso, región, unidad productiva o comunidades. En este contexto, la contraposición «reforma o revolución», como ya se decía en la década de 1950, es sencillamente contraproducente, en términos políticos y sociales. Hoy México vive un momento muy interesante donde la oposición a ciertas políticas llamadas «desarrollistas» o de «crecimiento» tienen adversarios muy importantes en el país y en algunos casos los sectores desheredados. Habrá que discutir democráticamente, con especificaciones muy prodigiosas en torno de las distintas posturas con el fin de examinar las consecuencias a corto y a largo plazo. En dicha discusión, tanto la «economía» como la «biología» tendrán que subordinarse a posturas éticas cuyo sustento será la base para reconstruir los universos económico-sociales. En otras palabras, ninguna de dichas disciplinas tiene el privilegio para establecer la ruta que debemos trazar; la toma de decisiones es imperativa, pero en un ámbito de discusión democrática, asumiendo plenamente las consecuencias sociales y ambientales. 


\section{CARLOS MALLORQUÍN}

\section{Referencias}

Chang, Ha-Joon (2004). Retirar la escalera: la estrategia del desarrollo en perspectiva histórica. Catarata/Instituto Universitario de Desarrollo y Cooperación/Instituto Complutense de Estudios Internacionales.

Mallorquín, C. (2017). América Latina y su teoría. Ariadna Ediciones/Colofón.

Ramiro Fernández, V. (2017). La trilogía del erizo-zorro: redes globales, trayectorias nacionales y dinámicas regionales desde la periferia. Anthropos/Universidad Nacional del Litoral.

Seers, D. (1979). «The birth, life and death of development economics (revisiting a Manchester conference)». Development and Change, 10, 707-719. 